\title{
Role of Semiconductors (Zinc Oxide as a Model) for Removal of Pharmaceutical Tetracycline (TCs) from Aqueous Solutions in the Presence of Selective Light
}

\author{
Liqaa H. Abd, Riyam Abbas, Aseel M. Aljeboree, Firas H. Abdulrazzak, Falah H. Hussein, Ayad \\ F. Alkaim
}

\begin{abstract}
In this work treatment of drug in wastewater using Zinc oxide ( $\mathrm{ZnO})$ nanoparticle as catalyst has been investigated. The effects of various parameters, such as the influence of initial drug concentration, time of irradiation, the effect of catalyst loading, he effect of intensity of light in order to reach to the optimum operational conditions in which the best treated of drug.The highest removal efficiency of drug was indicated at $0.2 \mathrm{gm} / 100 \mathrm{~cm} 3$ mass of Zinc oxide ( $\mathrm{ZnO})$ nanoparticle and $50 \mathrm{ppm}$ of drug . photocatalytic degradation of drug was favorable in the $7.33 \mathrm{~mW} / \mathrm{cm} 2$ light intensity. The percentage efficiency of removal drug equal $80.388 \%$ \%.The results explained the photocatalytic degradation efficiency, which was increased by increasing catalyst loading from $0.05 \mathrm{~g}$ to $3 \mathrm{~g}$. The degradation efficiency decreased with the increase in catalyst loading. Results also showed that the rate of photocatalytic degradation was increased with decreasing drug concentration.

Keywords : Zinc oxide(ZnO) nanoparticle, Light intensity, Pharmaceutical, Tetracycline, Photocatalytic.
\end{abstract}

\section{INTRODUCTION}

During the 1990s, Pharmaceuticals such as antibiotics, analgesics, lipid-regulating drugs, hormones, chemotherapy ,antiseptics and beta-blocking heart drugs were detected in wastewaters, ground-water, and streams resources across walled [1-3]. Although Pharmaceuticals had been detected previously sewage-treatment plants (STPs) $[4,5]$ and in effluent from landfills [6, 7], these more recent investigations indicated that some Pharmaceuticals are nearly ubiquitous at low concentrations in water bodies that receive STP effluent $[6,8,9]$.

Advanced oxidation processes (AOPs) concerned with the total oxidation of inorganic and organic materials by heterogeneous photocatalysis. In Photocatalytic oxidation the organic molecules were degradable in the presence of oxidizing agents such as oxygen or air and light ,semiconductor [10-13].zinc oxide is an excellent Photocatalytic oxidant for different types of pollutants in

Revised Manuscript Received on July 22, 2019.

Liqaa H. Abd, Riyam Abbas, Aseel M. Aljeboree, Firas H. Abdulrazzak, Falah H. Hussein, Ayad F. Alkaim

College of science for women-Chemistry Department/University of Babylon-Iraq, College of Education for Pure Sciences -Chemistry Department /Diyala University-Iraq, Almustaqbal University College, HILLA, IRAQ wastewater such as printing, pharmacy wastewater, papermaking wastewater and dyeing wastes[13] zinc oxide have good Photocatalyticproperties catalysts are nominated to be promising substrates for photo degradation of different organic pollutants under artificial and solar irradiation.and found that $\mathrm{ZnO}$ is more efficient than $\mathrm{TiO} 2-\mathrm{P} 25$ and TiO2-UV-100 in Photocatalytic degradation of drug; however, $\mathrm{ZnO}$ has the disadvantage of undergoing photo corrosion under illumination in acidic conditions[14-16].

\section{EXPERIMENTAL MATERIALS}

Commercial $\mathrm{ZnO}$ powder were purchased from (sigma-aldrich, Germany). Tetracycline (TCs) drug was supported by Samara Company of textile drug/ Iraq Chemical structure of Tetracycline (TCs). Fig 1. Freshly prepared aqueous solution of the pure drugs in a volumetric flask of $1000 \mathrm{~mL}$ by dissolving $0.1 \mathrm{~g}$ of drug TCs in distilled water All chemicals used in this study were analytical grade and used directly without further purification .

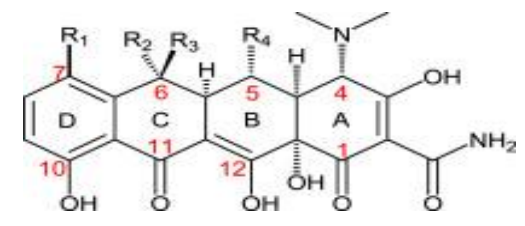

Figure 1: Chemical stretcher of Tetracycline (TCs) .

\section{PHOTO CATALYTIC EXPERIMENTS}

Zinc oxide with $99.5 \%$ purity was supplied by Carlo ERBA and used as supplied. InAll experiments of removal processes of drug have been performed by mixing $0.2 \mathrm{gm} / 100 \mathrm{~cm} 3$ of the catalyst with 50ppm of the drug solution. using a magnetic stirrer At predetermined times. $2 \mathrm{~cm} 3$ of suspension reaction mixture was withdrawn every $15 \mathrm{~min}$, and then centrifuged at 4000rps. The supernatant was carefully removed by a syringe with a long pliable needle the centrifugation was found very important to remove fine particles of $\mathrm{ZnO}$. The absorbance at $360 \mathrm{~nm}$ wavelengths of the supernatants was determined 
using ultraviolet-visible spectrophotometer (Apel-303 England). Photocatalytic reaction was carried out in a homemade photo reactor equipped with a Philips 125 $\mathrm{W} / 542$, high pressure mercury lamp (Holland) as a source for near-UV radiation.

\section{RESULT AND DISCUSSION}

\section{Effect of mass dosage}

To investigate the effect of catalyst loading on the final decolonization efficiency, a series of experiments were carried out by varying the catalyst from 0.5 to $3.0 \mathrm{~g} / \mathrm{L}$ in the solution with $50 \mathrm{mg} / \mathrm{Ldrug}$ concentration, reaction temperature $=25^{\circ} \mathrm{C}$, time $=1 \mathrm{~h}$. . The profile behavior of photo catalytic degradation is illustrated in Figure 2.

From Figure 2, results indicates that the rate of photo degradation increases by increasing the amount of $\mathrm{ZnO}$ upto $2 \mathrm{~g} / \mathrm{L}^{-1}$. Furthermore $2 \mathrm{~g} / \mathrm{L}^{-1}$, the rate of Photocatalytic degradation was taken a plateau region from $0.05-3 \mathrm{~g} / \mathrm{L}^{-1}$, then the rate of degradation decreased with increase in mass dosage $[15,17,18]$

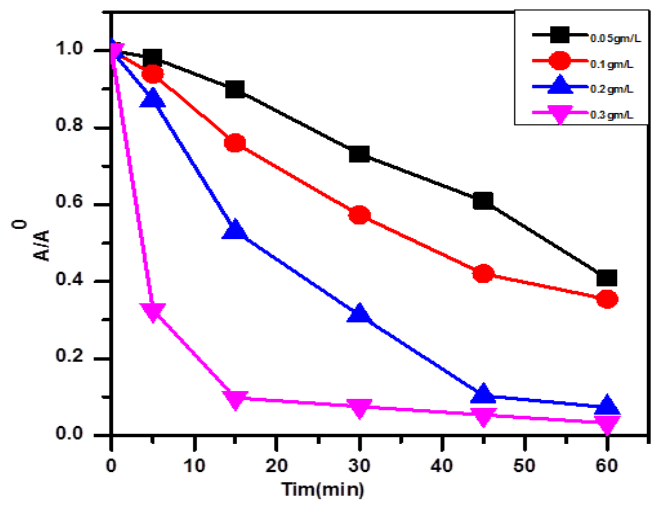

Figure 2:The effect masses of $\mathrm{TiO} 2$ on Photcatalytic degradation of Tetracycline (TCs) drug .

\section{The Effect of Initial Concentration of drug onRemoval Processes}

The removal of drug has been conducted by using different initial drug concentration in the range (10 - 80 ppm). These experiments was performed at range ( $0.2 \mathrm{gm} \mathrm{/} 100 \mathrm{~cm} 3)$, the suspension solution was irradiated with $7.33 \mathrm{~mW} / \mathrm{cm} 2$ intensity of light, flow rate of air bubble $10 \mathrm{~cm} 3 / \mathrm{min}$, at room temperature and 0.2 $\mathrm{gm} / 100 \mathrm{~cm} 3$ of $\mathrm{ZnO}$ nanoparticle as actuals . As illustrated in Figure 3 . the removal of drug decreases with increased the initial concentration of drug because the number of active site of $\mathrm{ZnO}$ nanoparticle catalyst doesn't change, so when the concentration of drug increases and cover all active sites that can cause reduced generation of an electron-hole pair which subsequently reduces the removal of drug[16]. The optimum concentration of drug was $50 \mathrm{ppm}$ the greatest removal of drug because the drug was cover the largest area of the $\mathrm{ZnO}$ nanoparticle particles, therefore absorbed maximum exciting photons to generate higher concentration of the activated catalyst show in figure 4 $[10,19,20]$

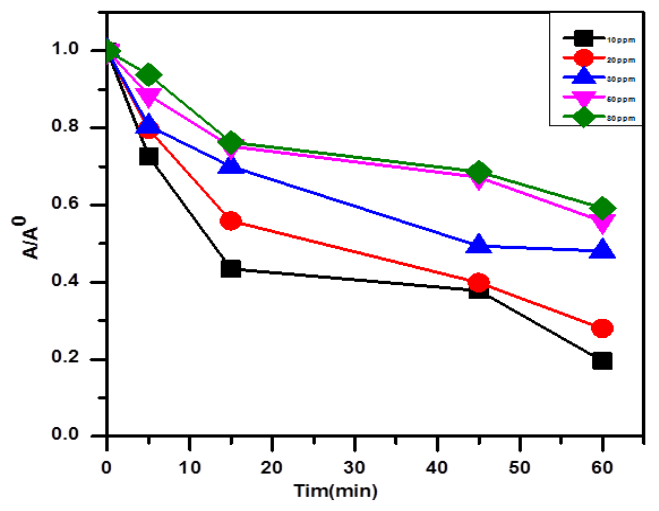

Figure 3: Photo catalytic degradation of Tetracycline (TCs) drug at different initial concentration.

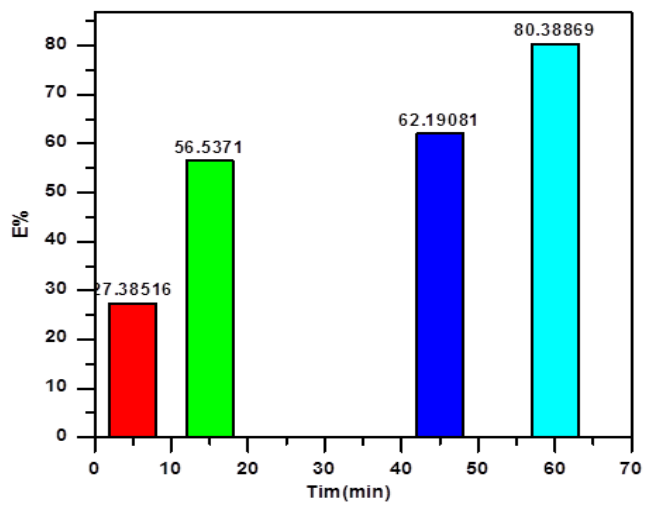

Figure 4: : percent removal Tetracycline (TCs) drug at different initial concentration.

\section{Removal of a real sample (pharmaceuticals Pollutant ) from aqueous solution.}

$100 \mathrm{ml}$ real sample (mixture of pharmaceuticals compounds)with a refry concentration were using in this study, then added beakers in the presence of $2 \mathrm{gL}^{-1}$ from $\mathrm{TiO}_{2}$, after that the mixture the beaker was put under the ultraviolet light maintaining the distance between the light source and the surface of the solution controlled by using UVA-meter (Dr. Honle/Germany)for $1 \mathrm{hr}$, after that the supernatant were separated by centrifuge and measured the remaining concentration by using UV-Visible spectrophotometer at a chosen wavelength at $360 \mathrm{~nm}$ show in figure 5 . and found when time increase the absorption decrease and gave higher percentage removal [21]. 


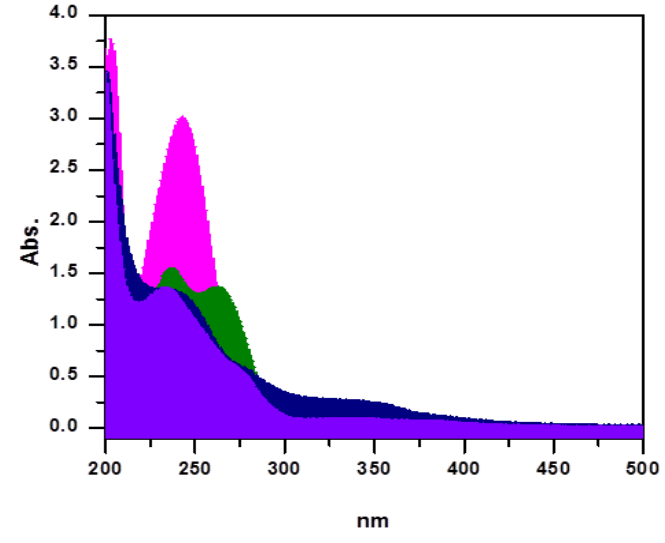

Figure 5: Removal of a real sample (mixture of pharmaceuticals compounds) by using $\mathrm{TiO} 2$

\section{CONCLUSION}

- Increasing the concentration of the adsorbent promoted an increase in the percentage of removal until saturation of the adsorbent.

- The percentage of removal decreased with increasing in the drug concentrations.

- The concentration of TCs drug 50 ppm gives the optimum Photocatalytic degradation efficiency which is equal to $80.388 \%$ after $60 \mathrm{~min}$.

- Removal of a real sample (pharmaceuticals Pollutant ) from aqueous solutionfound when time increase the absorption decrease and gave higher percentage removal.

\section{REFERENCES}

1. Stackelberg, P.E., et al., Persistence of pharmaceutical compounds and other organic wastewater contaminants in a conventional drinking-water-treatment plant. Science of The Total Environment, 2004. 329(1): p. 99-113.

2. H.R. Buser, T.P., M.D. Muller, Occurrence and environmental behavior of the chiral pharmaceutical drug ibuprofen in surface waters and in wastewater. Environ Sci Technol, 1999. 33(15): p. 252.

3. H.R. Buser, T.P., M.D. Muller, Occurrence and fate of the pharmaceutical drug diclofenac in surface waters: rapid photodegradation in a lake. Environ Sci Technol 1998. 32 (22): p. 3449.

4. Aseel M. Aljeboree , A.N.A., Adsorption of Pharmaceuticals as emerging contaminants from aqueous solutions on to friendly surfaces such as activated carbon: A review J. Pharm. Sci. \& Res. , 2018. 10(9): p. 2252-2257

5. Hignite, C. and D.L. Azarnoff, Drugs and drug metabolites as environmental contaminants: Chlorophenoxyisobutyrate and salicylic acid in sewage water effluent. Life Sciences, 1977. 20(2): p. 337-341.

6. Aseel Musthaq Aljeboree , A.N.A., Colorimetric Determination of phenylephrine hydrochloride drug Using 4-Aminoantipyrine: Stability and higher sensitivity J. Pharm. Sci. \& Res., 2018 10(7): p. 1774-1779

7. J.V. Holm, K.R., P.L. Bjerg, T.H. Christensen, Occurrence and distribution of pharmaceutical organic compounds in the groundwater downgradient of a landfill, Grindsted, Denmark. Environ Sci Technol,, 1995. 29(5): p. 1415.

8. T, T., Pharmaceuticals and metabolites as contaminants of the aquatic environment. In: Daughton CG, Jones-Lepp TL, editors. Pharmaceuticals and personal care products in the environment: scientific and regulatory issues. American Chemical Society, 2001.

9. B. Halling-Sorensen, S.N.N., P.F. Lanzky, F. Ingerslev, H.C.H. Lutzhoft, S.E. Jorgensen, Occurrence, fate and effects of pharmaceutical substances in the environment-a review. Chemosphere, 1998. 36(2): p. 357.
10. Kalithasan Natarajan, H.C., Bajaj Rajesh, J Tayade, Photo catalytic efficiency of bismuth oxyhalide $(\mathrm{Br}, \mathrm{Cl}$ and $\mathrm{I})$ nanoplates for $\mathrm{RhB}$ dye degradation under LED irradiation. Journal of Industrial and Engineering Chemistry, 2016. 34 p. 146-156.

11. Gulin Selda Pozan, A.K., Significant enhancement of photo catalytic activity over bifunctional $\mathrm{ZnO}-\mathrm{TiO} 2$ catalysts for 4-chlorophenol degradation. Chemosphere, 2014. 105: p. 152-159.

12. Ayad Fadhil Alkaim, Z.S., Dunia Kamil Mahdi, Saif Mohammed Alshrefi, Abdulkareem Mohammed Al-Sammarraie, Faisal Muhammad Alamgir, Preet Mohinder Singh, Aseel Mushtaq Aljeboree, Preparation, structure and adsorption properties of synthesized multiwall carbon nanotubes for highly effective removal of maxilon blue dye. Korean Journal of Chemical Engineering, 2015. 32(12): p. 2456-2462.

13. HUSSEIN, A.F.A.a.F.H., PHOTOCATALYTIC DEGRADATION OF EDTA BY USING TiO2 SUSPENSION. Int. J. Chem. Sci., 2012. 10(1): p. 586-598.

14. Aseel M. Aljeboree , A.S.A., Removal of Pharmaceutical (Paracetamol) by using CNT/ TiO2 Nanoparticles. Journal of Global Pharma Technology, 2019. 11 ( 01 ): p. 199-205.

15. Alkaim, A.F., Alrobayi, Enas $M$,Algubili, Abrar $M$ and Aljeboree, Aseel M, Synthesis, characterization, and photocatalytic activity of sonochemical/hydration-dehydration prepared $\mathrm{ZnO}$ rod-like architecture nano/microstructures assisted by a biotemplate. Environmental technology, 2017. 38(17): p. 2119-2129.

16. MUTHANA S. MASHKOURa, A.F.A.-K., LUMA M. AHMEDc and FALAH $H$. HUSSEIN, ZINC OXIDE ASSISTED PHOTOCATALYTIC DECOLORIZATION OF REACTIVE RED 2 DYE. Int. J. Chem. Sci., 2011. 9(3): p. 969-979.

17. Aseel M. Aljeboree, A.F.A., Ali loay2, hanadi m algburi, Photocatalytic Degradation of Textile Dye Cristal Violet Wastewater using Zinc Oxide as a Model of Pharmaceutical Threat Reductions. Journal of Global Pharma Technology, 2019. 11(3): p. 138-143.

18. Ye, Y., Y. Feng, H. Bruning, D. Yntema, and H.H.M. Rijnaarts Photocatalytic degradation of metoprolol by $\mathrm{TiO} 2$ nanotube arrays and UV-LED: Effects of catalyst properties, operational parameters, commonly present water constituents, and photo-induced reactive species. . Applied Catalysis B: Environmental, 2018. 220: p. 171-181.

19. Wei Zhou, L.z.Z., Denghui Jiang, Xinhua Zhong, Xinheng Li Enhanced Photocatalytic Degradation of Organic Dyes by Palladium Nano crystals. Journal of Nanoscience and Nanotechnology, 2016. 16: p. 7497-7502.

20. Leyva, E., et al., Photocatalytic degradation of ${ }^{2} \dot{\gamma}$-blockers in $\mathrm{TiO} 2$ with metoprolol as model compound. Intermediates and total reaction mechanism. Catalysis Today, 2019. 323: p. 14-25.

21. Aseel M. Aljeboree, H.Y.A.-G., Mohammed H. Said and Ayad F. Alkaim, THE EFFECT OF DIFFERENT PARAMETERS ON THE REMOVAL OF VITAMIN B12 DRUG (AS A MODEL BIOCHEMICAL POLLUTANTS) BY AC/ CLAY. Biochem. Cell. Arch. , 2019. 19(1): p. 755-759. 